\title{
Smart Algorithms and Psychological Warfare: Russian and Latin American Studies
}

\author{
Olga S. Polunina, Igor V. Romanov, Victoria A. Matanis, Mikhail V. Gundarin, \\ Maksim G. Chardymskiy* \\ Communicative Management Faculty, Russian State Social University, Moscow, Russia \\ * Corresponding author.Email: mchard@yandex.ru
}

\begin{abstract}
Since the process and then the notion of the psychological warfare has become the part of our life it is constantly changing, becoming more sophisticated. Radio and TV brought psychological warfare nearly in every house in the $20^{\text {th }}$ century. Internet and social media contributed greatly to the cross-boarding opportunities of psychological warfare. Modern stage is characterized by the appearance and development of smart algorithms and their integration into our life.

The research is mainly based on the theoretical analysis of the notion psychological warfare within the modern context. It is also aimed at defining the role and the influence of smart algorithms on the practice of psychological warfare in Russia and Latin American countries.
\end{abstract}

Keywords: smart algorithms, psychological warfare, manipulation, Internet, cyber security

\section{INTRODUCTION}

Smart algorithms used for calculation, data processing, and automated reasoning are being so deeply integrated into our daily routine that we merely has stopped thinking about them seriously. They help us with every sphere of our life whatever it may be: geography, networking, online shopping or just football. Short history of big data knows already a pretty good number of scandals with smartphones spying for their users, apps secretly collecting personal data and so on. Of course it is not that they are ruling the world but their use is becoming more widespread. These mathematical creations determine what you see in your Facebook feed, what movies Netflix recommends to you, and what ads you see in your Gmail. It also means that if they are so deeply rooted with our own life, modern psychological warfare is also based on them.

\section{METHODOLOGY}

The research is largely based on the theoretical analysis of the notion psychological warfare within the modern context. It is also aimed at defining the role and the influence of smart algorithms on the practice of psychological warfare.

The problem covered by this study is that few people really consider possible hazardous effect or manipulative possibilities. In these terms it is important to discover the answers to such questions that form the main research tasks: what objects are vulnerable to the implementation of smart algorithms? What actors are interested in their implementation? How can smart algorithms influence or even change the practice of the psychological warfare? For all these tasks such research methods as analysis and synthesis of existing studies about smart algorithms, ICT and modern conditions of communication are used.

Deduction method enables following from general peculiarities in theory to the application and implementation on practice under Russian and Latin American cases draw certain conclusions. Method of generalization is applied in order to emphasize common features and elements of problem in question.

\section{RESULTS}

The phenomenon of informational warfare is so deeply rooted in our life that it has become the object of scientific research for peaceful scholars specializing in different fields, not only military specialists. Philosophers study the new depths of human existence, sociologists study new forms of informational relations, even linguists study different connotations and shades of the meanings of informational warfare and informational attack.

Such interdisciplinary just outlines the fact that informational warfare is a large-scale, systematic and even transnational phenomenon. It is put in practice on different levels, executed by various actors but still has similar aims at achieving informational dominance. 
Actually informational warfare takes place in the informational or rather communication space which is in fact blurred, ambiguous and lacking any dimensions. In fact it's like virtual reality.

Total ambiguity and blur of the semantics of virtual space makes this issue extremely important especially within the framework of human security in the contemporary situation as this virtual space has a tremendous effect on the human consciousness while the human being is unable to counteract to its negative elements.

There is one more notion worth mentioning - global virtual space which is closely connected to the widely spread Internet. In this case we have to admit that virtual space is the object of attention not just numerous individuals but public consciousness as well.

Communication always occurs within the context. And it is not necessarily geographical. Actually it is not about national borders. Communication is about culture, about language, about people speaking that language. Latin America is actually mostly Spanish-speaking. And Spanish is the third most spoken language in the world. Latin America takes up to $10 \%$ of the global Internet audience [1] and there for $20 \%$ of those who prefer Facebook live in Latin America. Among them 95\% of consumers browse the internet before they decide on a car in Brazil and $90 \%$ in Colombia. There even appeared a neologism - internauta - user (like austranuat - exploring real space, they explore virtual one) in Spanish.

According to other sources, the share of Spanish-language content is negligible at only $5 \%$. There are other numbers - less than $30 \%$ of all content available in Latin America is in Spanish, which just fits within that 5\%. And this data is very revealing. After all, Spanish is actually the only language available to the indigenous people of Latin America. So they risk being left out of digital communication. But this is a problem only when viewed from one side. On the other hand, these are opening opportunities. Yes, low engagement is a challenge that keeps you on your toes and makes you look for answers to many questions. What if most of the communication is in another language? How to combine cultures? How to explain something that is not typical for another culture. This is the flexibility of thinking. You shouldn't boil everything down to mistakes and shortcomings of the Internet. Most of the content is entertaining and masks its potential. The main thing is not to be held hostage to this stereotype. And this also leads to the misperception that digital communications are already growing up.

But users and non-users tend to be discouraged if there are no locally relevant content. Sometimes it is important to provide information which can be of an influential power for the locals from weather forecasts to oil prices, but what important is that the content should be useful exactly for them. And it can be not only locally relevant, but also locally created.

There is obviously potential here. First, advertising and communication agencies will be able to find a new line of business that will work in partnership with international businesses, for example, help them understand local conditions and adapt their communications. Of course, this is a long-term perspective. But some Latin American companies were already ready for this challenge and are now open to flexible solutions. There are banks that are developing models of interaction with millennials, retailers or airlines that are considering the possibilities of new platforms, new models of work with personnel, expanding the capabilities and potential of employees towards creativity, innovation.

According to a current Reuters poll $83 \%$ of women in Bogota, Colombia, feel unsafe in mass transport; this is unfortunately the highest rate of any Latin American city [2]. On the one hand the quality of the system of public transportation is low. On the other there are digital ridesharing services which are viewed as a better alternative. And they are rather serious with this responsibility. Tappsi, a new app, now merged with Easy Taxi, uses an in-depth process to screen its drivers thus establishing truthfulness, credibility and reputation. The app provides a closed chat function that helps drivers and users communicate anonymously, do not share contact details and feel secure.

Let us consider the options for government and business in the field for interaction. For example, the government can provide funding and support to promote ICT usage at schools, can promote tech innovations and start-ups for the locals, can provide relevant content via e-government services and mobile internet providers and can contribute to enhancing digital literacy and awareness.

Education provides the foundation of holistic and inclusive development of the society [3]. Latin America can now be characterized with high literacy rates for both male and female (over 90\%) and high enrollment rates in primary and secondary schools (over $75 \%$ ). But nowadays in our digital ear however, it is also important to provide the young people with digital literacy. How can it be defined? More likely it is a set of skills that allows an internet user to not only access the internet and to browse websites, but evaluate the information, create the information, make use of digital devices. To start increasing digital literacy, think of raising your users' awareness of the role of digital communications, and then guide them down the path of specific digital skills. But digital literacy is not a cornerstone. Lack of modern equipment, good infrastructure will also hinder and keep the level of digitalization and technology penetration in Latin America at a low level.

The development of ICT and the fourth industrial revolution that we are witnessing is a combination of the digital, the physical and the human. When we talk about digital technology, we mean people. And if so, then for Latin America this is a problem. The job market there is always a balancing act between opportunity and limitations. Sustainable business plus innovation and ICT development represent tremendous opportunities for Latin American countries. What can be better? But the problem is that the fourth industrial revolution will inevitably lead 
to the reduction of jobs that require manual low-skilled labor. And many experts also predict the disappearance of traditional jobs or believe that this situation will bring about replacement for those that require digital skills, which are precisely what the majority of the population lacks [4].

Do you want to stay competitive and keep up with the times? Want it for the whole region? Try to start with people, not technology. Teach them, discover new skills, teach teamwork, project management, creativity, effective communication, English. It may not be too bad for now, but the shortage of information technology specialists who can master these progressive soft skills will grow. (By 2019 the lack was almost 500000 IT-professionals). But the biggest gap is just in the newly appeared area: cloud technologies, big data, data-driven-marketing, cybersecurity, information and psychological warfare, and so on. There will be demand and these vacancies may be filled by others, not the locals. This is a serious problem for the region. The researches [5] show that alongside with the technical skills the personnel should be trained in soft skills like problem solving and good communication skills, like 4Cs.

Any country can suffer from both a lack of jobs and a shortage of specialists, these are like two sides of the same coin. But this situation is especially toxic for developing countries with social tension, with an economic crisis and political instability. Unfortunately, these attributes are so familiar to the countries of Latin America.

If one ask about the most important requirement for fruitful actions in the sphere of informational warfare it can be creating successful inner and outer conditions for putting mechanisms of concealed or latent management by mean of informational expansion. It should be a priority to learn how to supervise strategic resources, provide cybersecurity, support national media and the entire information structure, the virtual space, channels and sources of communication, control the activity of other actors in one's own information field.

Russian researcher [6] insists on the introducing the term of "strategic information" because within the growing amount of information which is not structured only strategic approach will work. It means that there are some strategic goals and communication actors made certain attempts to process the information and then make use of it.

American specialists on the other hand arose the question of data hygiene. But big data has an Achilles heel: dirty data. Dirty data, which manifests in a multitude of different forms-duplicate data, inaccuracies, and duplicate information, for example--represents the single greatest threat to big data. It wreaks havoc on a company's bottom line, costing companies a staggering $12 \%$ of overall revenue [7]. Besides, data is a new resource suitable for extracting and processing and contributes to the existing scope of problems [8]. Poisoning the data is just on of the possible ways of malicious use of data, informational technologies [9].
The drawback that characterizes the region of Latin America is that adoption of ICTs is slow, not extensive. Of course the large firms normally have access to the Internet but more important is to adopt advanced technologies as soon as possible. This process is slow. As for small businesses they simply lag behind unlikely to catch up. What is more, according to the statistics [10] few groups of population have high broadband access. All these disadvantages exacerbate the situation.

In any case the sector of ICT is thought to be strategic. Brazil, for example, is putting a lot of faith in its IT sector. In March 2018, the government announced a joint investment with chipmaker giant Qualcomm to the tune of \$200 million to construct a semiconductor manufacturing plant in the country. While it's a big investment, the Qualcomm facility is expected to employ around 1,200, which will only slightly chip away at the country's $13 \%$ unemployment rate [11].

Mass media channels are one-way instruments of informational and communicational influence by their owners on the information consumers. Quite often this influence is latent, unconscious or even beyond one's will. Of course there a way out how to avoid manipulation just to switch off the channel. That's simple but not easy. It means that you will stay cut out from any informational flows. It is obvious that modern society suggests meeting not only physical needs but informational as well. Staying cut out you won't meet your informational needs. And so whatever is spread over these channels the consumer is not able to counteract the source of informational influence and is forced to consume the information as it is. In fact it is not just informational or psychological influence. It is informational and psychological violence. And what I mean is not exactly about classical mass media and their manipulative effect which is very well known. It may be for example social media platforms which are normally believed to be an alternative source of information, many believe that unbiased information. One of the latest examples how it usually happens is the case of fire in Russian shopping centre "Zimnyaya Vishnya". The official information of 67 victims was not inspiring. And there was a viral spread of 500 victims, overcrowded mortuaries and trucks with dead bodies. Within several days it was next to impossible to stop this insanity, there was social unrest and street protests. This fact shows that personal informational and psychological security of practically every Russian was at risk. Emotional context of this virtual reality left no chance to be rational. And to switch this reality together with the channels was also impossible.

There isn't any ready-made matrix for personal informational security in Russia, but some specialists in communication after the event with the fire in the shopping centre suggested some behavioral pattern in the Internet for ordinary informational consumers during hard times. The first recommendation is to limit the amount of materials for reading up to 1-2 per day. Then it is better not to watch live videos or any videos showing the place 
of tragedy. Then it is good not to listen or read any comments of so called witnesses. And finally if you read a text and you see a lot of adjectives, stop reading it. As it is meant not to inform but influence.

Alongside with times of crisis informational warfare can be executed at any time and in an unusual, unpredictable way. For example in the Russian segment of Internet just several weeks ago there was viral spread of information about news from the USA. The idea was that the US congress voted on the $27^{\text {th }}$ of June for accepting CostaRica as the 51 state of the USA. At first sight it seems to be a silly joke. But this joke has quite a certain aim that is discreditation of Russian internet resources specializing in geopolitics. Anyone who is at least slightly familiar with international relations or geopolitics knows that it was Puerto-Rico, not Costa-Rica that was eager to join the USA. And even brief visit to a website of the US Congress shows the fake character of this news which has family names, and even a quotation of the minister of the foreign affairs of Costa-Rica. As if he were showing his indignation to this violent act on behalf of the powerful neighbor.

Transnational brands also play an important role in the development of the process of informational warfare. For example they collect personal data and spy for their customers. If you take into account only economical point of view - that's ok and you do not notice any danger. Is it a big problem if a mobile app of a famous brand records your mobile screen? Or website uses cookies? Or tracing your geo-tag a brand can follow you and when you are close to the company store you will be offered a personal discount in an email on your mobile phone.

But transnational business is less an economic actor and more a political one because it operates in the international arena. International arena is the place where politicians perform. It means that transnational business is the party concerned about informational dominance as well. For example switched on geo-tag can show typical or not typical behavior of its owner - where he usually stays at night, where he is now. On a national scale this information can be of great importance.

The problem with artificial intellect, machine learning and smart algorithms is rather a social one. For example there are algorithms used for music, films or other content recommendations. What will be the consequences of these algorithms for the cultural life, for social life? The algorithms will be able to influence people's tastes and preferences. And a manipulative one: it depends on the developer, on the owner of the technology. And it can be true for reading recommendations, news recommendations. People's main weapon which is critical thinking falls asleep as it relies on recommendations and we know that technologies are in the first place advanced and in the second place unbiased that is why we rely on them. Isn't it a wide field for psychological warfare?

Russian psychologist Andrey Kurpatov describes one more interesting phenomenon - the illusion of knowledge. His main idea is that our knowledge is based on the environment which is limited be our outstretched arm everywhere and everything we can reach is familiar or known to us. Imagine you take a stick. It is like any instrument - with a stick your arm becomes longer and your horizons broaden. But in our modern world this stick is replaced by gadgets with Internet and they create the illusion of knowledge.

\section{CONCLUSION}

Now it only seems to us that we know a lot. And that is why it is so easy to manipulate and so difficult to resist manipulation as we believe that if know the Internet or lovely smartphone there can't be any manipulations. And that is why it is a fruitful ground for informational warfare, for informational violence because this is the way the illusion of knowledge works. And by the way it concerns not only manipulations, it is also true about terrorist recruitment based on this illusion. Big problem is that there are no any international or national legal regulations and standards which would help classifying hostile, malicious or manipulative actions in the informational sphere. There is not a united approach to evaluate moral or any other harm of these actions, no criteria to estimate the degree of aggression.

\section{REFERENCES}

[1] Internet Usage Statistics for all the Americas, 2016, Available at:

http://www.internetworldstats.com/stats2.htm.

[2] C. Vasques, How innovative companies are transforming Latin America, World Economic Forum, 05.06.2016, Available at:

https://www.weforum.org/agenda/2016/06/howinnovative-companies-are-transforming-latin-america.

[3] Connected Society, Digital inclusion in Latin America and the Caribbean, 2016, Available at: https://www.gsmaintelligence.com/research/?file $=895 \mathrm{f}$ 6c0a1efa7a25f5d6b4ff874e92f1\&download.

[4] J. Botifoll, Creating (and filling) jobs in Latin America's new digital economy, World Economic Forum, 14.04.2017, Available at:

https://www.weforum.org/agenda/2017/04/creatingand-filling-jobs-in-latin-america-s-new-digitaleconomy.

[5] J. Botifoll, Filling the IT Skills Gap in Latin America with Qualified IT Talent, Cisco Blogs, 05.08.2016, Available at: 
http://blogs.cisco.com/news/filling-the-it-skills-gap-inlatin-america-with-qualified-it-talent.

[6] T. Andreeva, Strategic information and modern methods of its processing, Information security of the regions 3 (2014).

[7] F. Fatemi, Best practices for data hygiene, Forbes, 30.01.2019, Available at:

https://www.forbes.com/sites/falonfatemi/2019/01/30/b est-practices-for-data-hygiene/\#45c378232395.

[8] N. Couldry, U. Mejias, The Costs of Connection, Stanford University Press, 2019.

[9] Malicious Use of Artificial Intelligence and International Psychological Security in Latin America, ICSPSC, 2020.

[10] J. Gallego, L. Guttierez, ISTs in Latin America and Caribbean firms, Discussion paper No IDB-DP394, Inter-American Development Bank, 2015.

[11] J. Keane, Latin America trends 2018: ICT will start to find its feet again, 2018, Available at: https://www.cio.com/article/3249529/latin-americatrends-2018-ict-start-feet.html. 